\title{
The Feasibility of a Text-Delivered Intervention to Improve Dietary Habits, Stress Management Behaviors and Create Awareness of Food Assistance Resources Among College Students
}

\author{
Dorcas R Mukigi and Onikia Brown* \\ Department of Nutrition, Dietetics, \& Hospitality Management, Auburn University, USA
}

Submission: November 13, 2019; Published: December 02, 2019

"Corresponding author: Onikia Brown, Department of Nutrition, Dietetics, \& Hospitality Management, Auburn University, USA

\begin{abstract}
Food insecurity in college students is associated with lower self-reported health, poor dietary habits, inadequate sleep, mental health issues, and lower grade point average (GPA). This study aimed to evaluate the acceptance and effectiveness of health-related text messages on college students' dietary habits, stress management behaviors and awareness of food assistance resources. Forty-six college students with mobile phones were recruited during the Spring semester 2018. The intervention group received 3 messages per week for 7 weeks and the control group received the same information in an email attachment at post-intervention. A pre and post online survey assessed the students' fruit and vegetable intake, perceived stress, hours of sleep and awareness of food assistance resources. The intervention group significantly $(\mathrm{p}<0.05)$ reduced perceived stress from baseline $27.71 \pm 5.18$ to $17.33 \pm 5.20$ and increased intake of fruit and vegetable by 0.5 cups/day at post-intervention. Text delivered messages appear to be acceptable and have the potential to promote positive dietary habits, stress management behaviors, and create awareness of food assistance resources among college students.
\end{abstract}

Keywords: College Students; Text Messages; Stress; Sleep; Fruits and Vegetables; Sugar Sweetened Beverages

Abbreviations: GPA: Grade Point Average; SSB: Sugar Sweetened Beverages; NHNES: National Health and Nutrition Examination Survey; ACHA American College Health Association; IRB: Institutional Review Board; USDA: United States Department of Agriculture

\section{Introduction}

College students, often referred to as emerging adults, experience transitions in health-related behaviors as they adapt to life in college [1]. This transitional period is characterized by changes in dietary habits, stress and mealtime behaviors [2-5]. Additionally, emerging adults often lack resources and skills required for food preparation. These factors contribute to their increased risk for food insecurity [6,7]. Dietary habits that are consistent with the national dietary guidelines have been found to promote health, but college students do not meet these guidelines [8-10]. Studies have reported that college students have poor dietary habits and they do not meet their recommended daily intake of fruit and vegetable $[9,11,12]$. One study that examined the relationship between food insecurity and fruit and vegetable intake among college students found that food insecure students ate significantly lower daily servings of fruit and vegetable as compared to students with high food security controlling for confounding factors such as car access, race/ethnicity and gender [13]. College students also skip meals, consume high amounts of snacks and high calorie food items such as sugar sweetened beverages (SSB) $[14,15]$. Furthermore,
National Health and Nutrition Examination Survey (NHNES) data indicate that young adults - age category in which most college students fall under, have the highest mean percentage of daily calories from SSB [16].

College students are prone to stress due to the transitional nature of college life [17]. According to the American College Health Association (ACHA) national survey, 57\% of college students report elevated levels of stress [18]. Stress among college students is caused by numerous factors including adjusting to life away from family, developing relationships, need to maintain high level of academic achievement, juggling time demands from school and work, and increased responsibilities [19]. These stressors bring about change in sleeping patterns and may influence sleep quality and quantity $[4,17]$. Studies have shown that a majority of college students do not meet the recommended 9 hours of sleep per night $[4,17]$. Sufficient sleep quality and quantity are critical determinants of health, and recently the US government added sleep as an objective in Healthy People 2020 [4,17,20]. There is need for campus administrators and researchers to come up with interventions 
and avail information on stress management to help students cope better with stress.

Mobile phones have been used to provide widely accepted and inexpensive medium in which health related information can be communicated to the targeted populations [21,22]. In a study conducted by Pew Research Center, $94 \%$ ( $\mathrm{n}=273$, aged 18-26 years) of college aged students reported having mobile phones and $89 \%$ reported having their phones in near proximity all the time, including bedtime [23]. College students with mobile phones reported receiving and sending a mean of 119 text messages a day.24 With the incorporation of text messaging in the day-to-day lives of college students, it provides opportunities in which behavior change interventions can be delivered in a platform that is popular and easily accessed by the target population [23-25]. The time that students spend in college is critical for the development of lifelong habits. Therefore, researchers should be deliberate in evaluating health behaviors in this age group and in providing appropriate and directed health education and information to improve health behaviors for optimum health outcomes. The purpose of this study was to evaluate the effectiveness of using text delivered messages to improve college students' dietary habits, stress management behaviors and create awareness of food assistance resources.

\section{Methods}

This study was approved by the University's Institutional Review Board (IRB). An email was sent to conveniently selected professors in the college of human sciences requesting them to send a recruitment email with a link to the 6 item United States Department of Agriculture (USDA) food security survey to their classes. The same recruitment email was sent to on campus food pantry and Campus Kitchen mailing list. The Campus Kitchen is a student led program that fights hunger on campus and in the community by collecting unserved food from dining halls and redistributing it to those in need. To protect the identity of those who receive assistance from the food pantry and Campus Kitchens, the recruitment email was sent by the concerned staff and faculty. Inclusion criteria were age $\geq 18$ years and regular access to a mobile phone with a texting plan. When $50 \%$ of the target population of either food secure or insecure was achieved, participation was closed for that category. The participants were randomly assigned to the control or intervention group based on their food security status in the order that they completed the online survey. The participants completed an online survey powered by Qualtrics survey Software (version 2018; Qualtrics Provo, Utah) at baseline and post-intervention.

The survey included a consent letter, demographic data form, food assistance resources awareness and utilization data collection tool [26], National Cancer Institute fruits and vegetables screener [27], sugar sweetened beverage screener [15], Cohen's Perceived Stress screener [28], hours of sleep [29], and meal behavior data collection tool [5]. At post-intervention, the intervention group were asked to state the number of text messages they read during the intervention, what they liked most about the messages and to suggest their preferred medium for receiving health information. The intervention messages were developed from formative interview data, tested using cognitive interviews [30], and organized in 3 major themes: eating habits, stress management and food assistance resources awareness. The intervention group received 3 text messages per week for 7 consecutive weeks that contained information to encourage healthy dietary habits, stress management strategies and food assistance resources. The intervention participants were instructed during the consent process to text "STOP" if they no longer wished to receive text messages at any point in the study. The control group received an email attachment containing all the messages at the end of the study. The participants were compensated for completing surveys ( $\$ 5$ at baseline and $\$ 10$ at post-intervention).

\section{Measures}

\section{Demographics}

Demographic information including age, classification, gender and race/ethnicity were assessed at baseline.

\section{Anthropometrics}

Participants reported their weight (pounds) and height (feet and inches) respectively. These measurements were then transformed to kilograms $(\mathrm{kg})$ and meters $(\mathrm{m})$ to calculate body mass index (BMI) by: $(\mathrm{BMI}=$ weight $(\mathrm{kg}) /[$ height $(\mathrm{m})] 2$. BMI of each participant was classified as either underweight $(<18.5)$, normal (18.5-24.9), overweight (25.0-29.9) and obese $(\geq 30)$ [31]. Weight was a secondary study outcome.

\section{Food Assistance Resource Awareness}

Questions to assess awareness and utilization of food assistance resources were adapted from a similar study.26 Participants were asked, "Are you aware of places on campus where you can receive supplemental food if needed?", and "Is there a food pantry on campus?" Those who answered "yes" were asked, "Have you ever used the on-campus food pantry or received free meals offered by the Campus Kitchens?", if they answered "yes", they were asked, "How times a semester do you get food from campus food pantry or Campus Kitchens?" Feelings towards utilizing the food pantry were also measured by asking the following question, "Please tell us how you may feel should you ever need to receive food from the food pantry or Campus Kitchens". The participants were asked to rate each of the following feelings: encouraged, supported, satisfied, ashamed, embarrassed or loss of self-respect on a scale from 1 to 5; 1 = strongly disagree, 2 = agree, 3 = neither agree or disagree, $4=$ disagree and $5=$ strongly disagree. Participants likelihood to use food assistance resources were evaluated by asking the participants the following questions,

"Please tell us how likely you are to use the following resources: 
i) Ask parents, friends, relatives, or partner to send money,

ii) Ask parents, friends, relatives, or partner to send/ purchase food,

iii) Attend events offering free food,

iv) Borrow money or

v) Dumpster dive to receive food assistance.

Responses were;

i) Extremely likely

ii) Moderately likely

iii) Neither likely or unlikely

iv) Moderately unlikely

v) Extremely unlikely.

\section{Fruits and Vegetables Intake}

The short form National Cancer Institute fruits and vegetables screener [27] was used to assess intake of fruit and vegetable as cups per day. This screener measures the frequency and average consumption of fruits and vegetables over the last one month. The variables data were transformed to cups per day before analysis.

\section{Sugar Sweetened Beverage (SSB) Intake}

An adapted 8 question instrument15 was used to assess the frequency and quantity intake of SSB in the previous month. The SSB queried included non-diet soda, fruit drinks, non-diet energy drinks and sweetened tea. The responses for frequency were never or less than 1 per month, 1-4 per month or 2-6 per week and the responses for quantity included none (all SSB), $12 \mathrm{oz}$ can, restaurant glass/cup, $20 \mathrm{oz}$ bottle (soda and fruit drinks), or 2 liter (soda) or $64 \mathrm{oz}$ bottle (fruit drinks), 2 to $16 \mathrm{oz}$ energy drinks, and $\leq 12 \mathrm{oz}$, or $\geq 12 \mathrm{oz}$ sweetened tea. The average number of kilocalories per day from SSB consumption were computed by converting amounts and frequency into ounces per day and multiplying by respective kilocalories per ounce.

\section{Mealtime Behavior}

An adapted instrument [5] for measuring healthful mealtime behavior was used to assess mealtime planned self-regulation and self-instruction.

For self-regulation, the participants were asked to specify how often in the last 3 months they had:

i) Purposely added vegetables to their meals and snacks,

ii) Planned quick, easy and healthy snacks,

iii) Selected beverages with health in mind,

iv) Been flexible and sensible in food choices.
To assess self-instruction for healthful mealtime behavior, participants were asked how often in the past 3 months they had:

i) Told myself to allow room for an occasional treat food or dessert for just plain enjoyment,

ii) Told myself fruits and vegetables should be included in every meal,

iii) Reminded myself to eat in moderation,

iv) Reminded myself that healthy meals do not require a lot of work,

v) Reminded myself that planning quick and simple meals is important,

vi) Reminded myself to think about my beverage choices". The responses were on a 5-point Likert scale: $1=$ never, 2 = sometimes, 3 = regularly, $4=$ often and $5=$ always. Higher scores indicate healthful mealtime behaviors.

\section{Perceived Stress}

Cohen's Perceived Stress Scale (10-item) 28 was used to measure participants perceived stress. This scale appraises the degree to which individuals find situations in their lives as stressful. The scale asked how overloaded, unpredictable and uncontrollable the participants found their lives in the last one month. The responses were on a 5-point Likert scale with $0=$ never, 1 = almost never, 2 = sometimes, 3 = fairly often, and $4=$ very often. Questions $4,5,7$ and 8 were positively worded and therefore scores were reversed $(0=4,1=3,2=2,3=1$ and $4=$ $0)$. Higher scores indicate high perceived stress.

\section{Hours of Sleep}

Participants were asked to report the average number of hours they sleep in a 24-hour period. This question is drawn from the Behavior Risk Factor Survey [29].

\section{Text Message Evaluation}

During the study, the intervention group participants were asked to reply "yes" to text messages to indicate that they had received and read the intervention messages. Additionally, at post-intervention, intervention group participants were asked to report if they received and read the messages and indicate the number of messages they read. At post-intervention, the intervention participants were asked to suggest preferred medium (s) of message delivery and improvements for the intervention messages. The control participants were asked to suggest their preferred method of health information communication at post-intervention.

\section{Data Analysis}

The data were analyzed using SPSS statistical software program (version 23; IBM SPSS, Armonk, New York). Descriptive statistics were used to analyze baseline demographic, food security status and anthropometric characteristics (BMI) and 
were expressed in frequencies and percentages. Chi square analysis were used to analyze differences in categorical data. Oneway analyses of variance (ANOVA) was used to assess bivariate associations between food security status and fruit and vegetable intake, calories from sugar sweetened beverages, perceived stress scores, hours of sleep and weight of all participants at baseline. To determine differences between intervention and control group outcome variables, repeated measures ANOVA were performed. Significance was reported for time, group and group x time. Data from participants who did not complete postintervention survey were excluded in the final analysis. $P$ values $\leq 0.05$ were considered as statistically significant.

\section{Results}

\section{Participants}

Seventy-nine individuals started the screening survey, 76 completed the screener and 46 consented to participate in the study. Forty-four participants completed the post-intervention survey, of which 21 were intervention participants (96\% retention). Majority of the participants in both groups were aged between $18-24$ years (63\%), were graduate students $46 \%$, White $(67 \%)$ and were categorized as "normal weight" (63\%) based on BMI (Table 1).

Table 1: Characteristics of Study Participants at Baseline.

\begin{tabular}{|c|c|c|c|}
\hline & $\begin{array}{c}\text { Intervention } \\
(\mathbf{n = 2 2 )}\end{array}$ & $\begin{array}{c}\text { Control } \\
(\mathbf{n = 2 4 )}\end{array}$ & Total (n=46) \\
\hline Characteristic & & & \\
\hline Demographics (\%) & & & \\
\hline Age & & & \\
\hline $18-24$ & $12(55)$ & $17(71)$ & $29(63)$ \\
\hline$\geq 25$ & $10(45)$ & $7(29)$ & $17(37)$ \\
\hline Classification & & & \\
\hline Sophomore & $4(18)$ & $2(8)$ & $4(13)$ \\
\hline Junior & $4(18)$ & $6(25)$ & $10(22)$ \\
\hline
\end{tabular}

\begin{tabular}{|c|c|c|c|}
\hline Senior & $4(18)$ & $5(21)$ & $9(20)$ \\
\hline Graduate & $10(45)$ & $11(46)$ & $21(46)$ \\
\hline \multicolumn{4}{|l|}{ Gender } \\
\hline Male & $4(18)$ & $5(21)$ & $9(20)$ \\
\hline Female & $18(82)$ & $19(79)$ & $37(80)$ \\
\hline \multicolumn{4}{|l|}{ Race/Ethnicity } \\
\hline African American & $1(5)$ & $0(0)$ & $1(2)$ \\
\hline White & $14(64)$ & $17(71)$ & $31(67)$ \\
\hline Hispanic or Latino & $2(9)$ & $2(8)$ & $4(9)$ \\
\hline Asian & $5(23)$ & $3(13)$ & $8(17)$ \\
\hline Multiracial & $0(0)$ & $2(8)$ & $2(4)$ \\
\hline \multicolumn{4}{|l|}{ Food Security Status } \\
\hline Food secure & $10(45)$ & $10(42)$ & $20(43)$ \\
\hline Food insecure & $12(55)$ & $14(58)$ & $26(57)$ \\
\hline \multicolumn{4}{|l|}{$\begin{array}{c}\text { Anthropometric } \\
\text { measurements (\%) }\end{array}$} \\
\hline \multicolumn{4}{|l|}{ Body Mass Index } \\
\hline Underweight & $1(4)$ & $0(0)$ & $1(2)$ \\
\hline Normal weight & $14(58)$ & $15(68)$ & $29(63)$ \\
\hline Overweight and Obese & $9(36)$ & $7(32)$ & $16(35)$ \\
\hline
\end{tabular}

\section{Eating Behavior}

At post-intervention, although not statistically significant, the intervention participants increased their daily fruit and vegetable intake by half a cup whereas the control group intake remained essentially the same as measured by the National Cancer Institute fruits and vegetables [27]. The intervention and control group reduced the calories from the intake of SSB by 19 and 30 calories, respectively. Planned self-regulation and reported self-instruction scores for healthful mealtime behavior at baseline and post-intervention were approximately 3 on a scale of 1 to 5 for both groups, with higher score indicating greater intention for behavior change or current behavior (Table 2).

Table 2: Comparison of Intervention and Control Group Study Outcomes (Eating behavior, Perceived Stress, Sleep Hours, Mindful Eating and Weight) at Baseline and Post-intervention.

\begin{tabular}{|c|c|c|c|c|c|c|}
\hline & & & & Significance $^{\mathrm{a}}$ & & \\
\hline Characteristic & & Baseline (Mean \pm SD) & Post-Intervention (Mean \pm SD) & Time $^{b}$ & Group & $\begin{array}{c}\text { Group X } \\
\text { Time }\end{array}$ \\
\hline \multicolumn{7}{|c|}{ Eating behavior } \\
\hline \multirow{2}{*}{$\begin{array}{l}\text { Fruits and vegetables intake, } \\
\text { cup } / \mathrm{d}\end{array}$} & Intervention & $2.94 \pm 0.79$ & $3.41 \pm 0.92$ & 0.174 & 0.439 & 0.345 \\
\hline & Control & $2.89 \pm 1.73$ & $2.98 \pm 1.15$ & & & \\
\hline \multirow{2}{*}{$\begin{array}{l}\text { Sugar sweetened beverages, } \\
\text { kcal/day }\end{array}$} & Intervention & $80.81 \pm 134.7$ & $62.31 \pm 126.94$ & 0.469 & 0.703 & 0.864 \\
\hline & Control & $102.70 \pm 248.39$ & $72.81 \pm 166.41$ & & & \\
\hline \multicolumn{7}{|c|}{ Mealtime behavior } \\
\hline \multirow{2}{*}{$\begin{array}{l}\text { Planned self-regulation for } \\
\text { healthful mealtime behavior }\end{array}$} & Intervention & $3.29 \pm 0.73$ & $3.30 \pm 0.79$ & 0.514 & 0.551 & 0.6 \\
\hline & Control & $3.35 \pm 0.73$ & $3.49 \pm 0.95$ & & & \\
\hline \multirow{2}{*}{$\begin{array}{l}\text { Reported self-instruction for } \\
\text { healthful mealtime behavior }\end{array}$} & Intervention & $3.38 \pm 0.99$ & $3.37 \pm 0.90$ & 0.97 & 0.286 & 0.898 \\
\hline & Control & $3.12 \pm 0.722$ & $3.14 \pm 0.84$ & & & \\
\hline
\end{tabular}


Annals of Reviews and Research

\begin{tabular}{|c|c|c|c|c|c|c|}
\hline \multirow{2}{*}{ Sleep, hours/d } & Intervention & $7.00 \pm 1.41$ & $7.10 \pm 1.41$ & 0.104 & 0.885 & $0.037^{*}$ \\
\cline { 2 - 7 } & Control & $7.40 \pm 1.37$ & $6.61 \pm 1.03$ & & $0.000^{*}$ & 0.068 \\
\hline \multirow{2}{*}{ Perceived stress } & Intervention & $27.71 \pm 5.18$ & $17.33 \pm 5.20$ & & 0.567 \\
\cline { 2 - 7 } & Control & $29.61 \pm 6.28$ & $20.43 \pm 5.69$ & 0.716 & 0.424 & 0.565 \\
\hline \multirow{2}{*}{$* *$ Weight } & Intervention & $63.20 \pm 11.04$ & $63.93 \pm 11.46$ & & \\
\cline { 2 - 7 } & Control & $63.88 \pm 20.83$ & $67.98 \pm 16.46$ & & \\
\hline
\end{tabular}

\section{Hours of Sleep and Perceived Stress}

At baseline, the food secure students had more hours of sleep than the food insecure students $(7.90 \pm 1.29$ vs $6.68 \pm 1.22$, respectively; $\mathrm{p}<0.05)$, Figure 1 . There was significant group $\mathrm{x}$ time interaction for sleep; the intervention group reported a higher number of sleep hours $(7.40 \pm 1.37)$ compared to the control group (6.61 \pm 1.03$)$ at post-intervention (Table 2). There was significant time interaction for perceived stress; the intervention and control groups significantly reduced perceived stress at when within group baseline and post-intervention scores were compared; $27.71 \pm 5.18$ to $17.33 \pm 5.20$ and 29.61 \pm 6.28 to $20.43 \pm 5.69 ; \mathrm{p}<0.05$ ), respectively (Table 2 ). For the secondary outcome of weight, there were no statistically significant differences when baseline and post-intervention measurements were compared for both groups (Table 2). However, food insecure students weighed significantly more than the food secure students at baseline and post-intervention $(60.93 \pm 14.76$ vs $69.94 \pm 12.86$, respectively; $\mathrm{p}<0.05)$, Figure 2 .

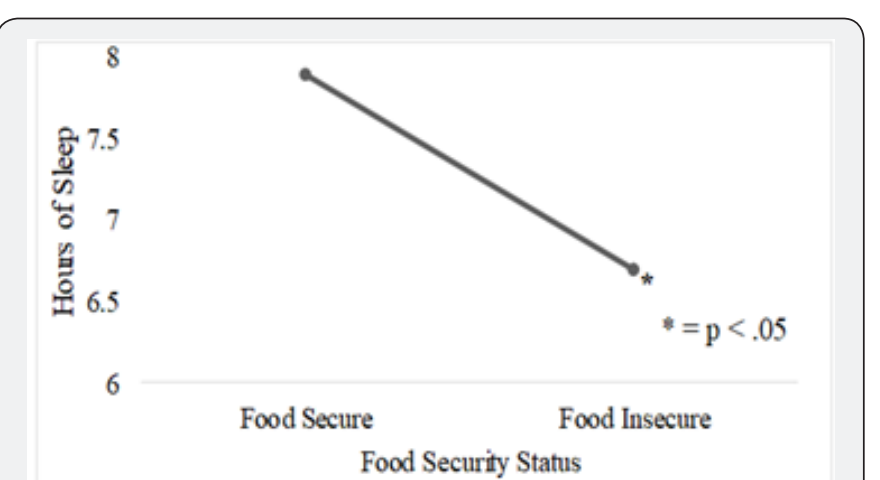

Figure 1: Baseline Differences in Hours of Sleep by Food Security Status.

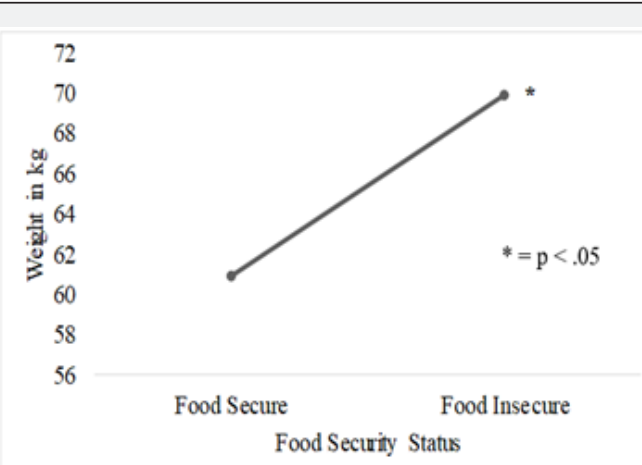

Figure 2: Post-intervention Differences in Weight by Food Security Status.

\section{Food Assistance Resource Awareness and Utilization}

At baseline, 39\% of the participants agreed that using the food pantry to get food assistance would make them feel encouraged, supported and satisfied (Figure 3). Also, the participants reported that they utilized the food pantry at least 4 times per semester. There was significant increase in the percentage of intervention participants who knew places on campus that provide supplemental food assistance and where the food pantry is located on campus (Table 3).

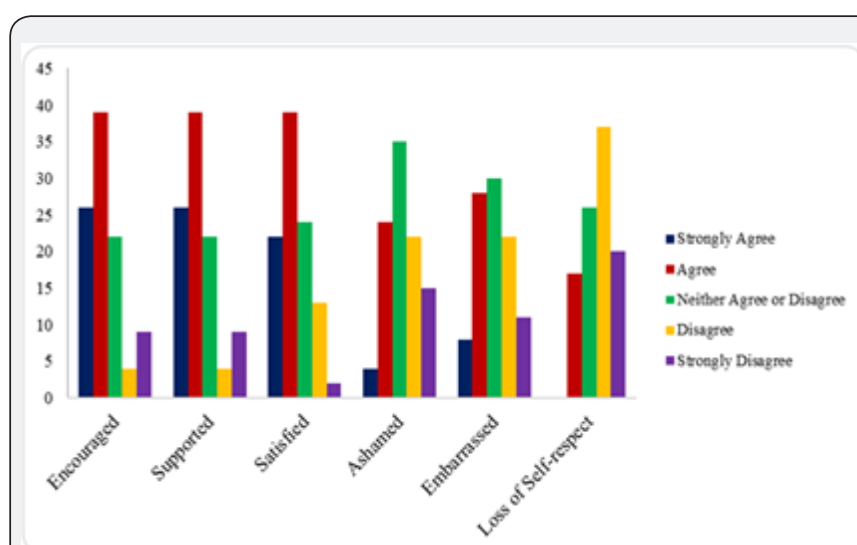

Figure 3: Study Participants Feelings About Utilizing the Food Pantry at Baseline $(n=46)$.

Table 3: Comparison of Intervention and Control Study Participants Food Assistance Resource Awareness at Baseline and Postintervention.

\begin{tabular}{|c|c|c|c|c|}
\hline & $\begin{array}{c}\text { Baseline } \\
\text { (\%) }\end{array}$ & $\begin{array}{c}\text { Post- } \\
\text { intervention } \\
\text { (\%) }\end{array}$ & $\begin{array}{c}\text { Change } \\
\text { (\%) }\end{array}$ \\
\hline $\begin{array}{c}\text { Are you aware } \\
\text { of places } \\
\text { on campus } \\
\text { that provide } \\
\text { supplemental } \\
\text { food? }\end{array}$ & Intervention & 77 & 100 & $23^{*}$ \\
\hline $\begin{array}{c}\text { Is there a food } \\
\text { pantry on } \\
\text { campus? }\end{array}$ & Intervention & 68 & 100 & $32 *$ \\
\hline & Control & 83 & 91 & 8 \\
\hline
\end{tabular}

Note: Results are presented based on percent affirmative answers given by participants. Chi square analysis were used to analyze the responses.

*Significant difference in the change in food assistance resources awareness between control and intervention group, $p<0.05$. 


\section{Text Message Evaluation}

One hundred percent of the intervention participants reported that they received and read the messages and there was $100 \%$ retention of participants. Fifty-seven percent of the intervention participants read 15-21 intervention text messages. Most of the control (70\%) and 38\% of intervention participants reported that email is their most preferred method to receive health information. Some of the suggestions for improvements include: "start an Instagram page to post healthy (food) pictures and ideas", "make messages participant specific" and "reduce the length of some of the messages." Two participants felt that the messages were "great".

\section{Discussion}

College students often have unhealthy dietary habits that include low intake of fruits and vegetables [3], and increased intake of fast foods and SSB $[14,15]$. Due to busy schedules and increased responsibility, college students have increased levels of stress and inadequate sleep $[17,18]$. Additionally, studies have shown that college students have increased risk of food insecurity due to increasing cost of attending college, developing food and financial management skills and limited income $[7,32]$. For these reasons, we assessed the effects of a 7-week text delivered intervention on eating habits (intake of fruit and vegetable, sugar sweetened beverages and mealtime behavior), perceived stress, and awareness of food assistance resources in a random sample of college students in a public university in southeast United States. As expected, at baseline, the intake of fruit and vegetable for both the intervention and control groups were consistent with that of other US college students and did not meet the recommended 5 or more daily servings of fruits and vegetables $[33,34]$. Although not statistically significant, the intervention group participants reported an increase in the intake of fruit and vegetable at post-intervention, whereas the control participants maintained their intake. Other studies reported similar outcomes in that there were small increases in fruit and vegetable intake at post-intervention [35-37].

These trends point to the existence of barriers to college students' intake of fruit and vegetable that includes access, costs and time constraints $[13,38]$. College students report that lack of grocery stores and transportation to access off campus stores as major environmental barriers to consumption of fruit and vegetable [38]. Furthermore, college students often have busy schedules and are on limited budgets and report not having time to purchase fruit and vegetable regularly and find their cost to be expensive, respectively $[13,38]$. Given the benefits of fruits and vegetables in health promotion, there should be continued interventions and campaigns to promote intake of fruit and vegetable intake among college students. Although there wasn't a significant difference in the calories from SSB between and within the intervention and control groups at baseline and at post-intervention, all the participants in this study reported lower intakes of sugar sweetened beverages compared to other young adults (20-34 years) in the US [39]. Similar findings were reported in two studies that evaluated the effectiveness of webbased and multi-modal interventions to modify dietary habits of college students in that they found no significant reduction in energy intake from SSB [2,35]. Increased intake of sugar sweetened beverages is positively associated with increased body weight and risk of obesity across all groups [40].

In the current study, a majority of study participants had normal BMI at baseline and at post-intervention. This can conservatively indicate that their normal BMI is linked with their low intake of calories from SSB. Although the intervention participants did not report significant changes in planned selfregulation and self-instruction for healthful mealtime behavior, their mealtime behavior scores at post-intervention were similar to those reported by other student samples [2]. Due to busy class schedules and assignments, college students often develop poor eating habits such as snacking on unhealthy food items and skipping meals [3]. Healthful mealtime behavior such as budgeting and shopping for food, planning regular meals and healthy snacks have been associated with healthy dietary habits and weight maintenance by college students [41]. Additionally, planning and tracking snacks and meals have been associated with reduced intake of SSB and greater intakes of fruit and vegetable [5]. It is important that healthful mealtime knowledge and skills are imparted on students early in their Freshmen years and continued throughout their college years. Increased levels of stress are positively associated with reduced hours of sleep [4]. In the current study, participants in the intervention and control group had less than the 9 recommended hours of sleep per day [5] and less than amounts (8.4 hours) reported in another study [4].

The intervention group participants maintained their hours of sleep while the control group significantly reduced their sleep time when baseline and post-intervention hours of sleep were compared. Perceived stress among the intervention group participants significantly reduced at post-intervention. These results indicate that the text delivered messages encouraging positive stress management behaviors and thus were successful in reducing the intervention participants perceived stress. Our study found that food insecure students utilize the oncampus food pantry at least 4 times a semester, this is twice the amount reported in a study that investigated predictors of food assistance resource use [26]. A recent study found that $30.8 \%$ of food insecure students were not aware of the existence of a food pantry on their campus [26]. Additionally, researchers reported that although $6.6 \%$ of food insecure students were aware of food assistance resources, only $2.3 \%$ utilized them [32]. As an increasing number of universities establish food pantries [42], it is important to make students aware of the existence of such resources and to initiate conversations with students in order to identify barriers and facilitators of resource use. Promising outcomes were observed in our study that used text delivered messages among college students. 
The $100 \%$ retention of the intervention participants may be attributed to the fact that text messaging is widely accepted and fully integrated into the lives of college students, and that text messages are not invasive. Also, the majority (57\%) of the intervention participants reported reading 15-21 intervention messages. At the end of the study, one participant stated, "I thought they (messages) were great" this indicates acceptability of receiving health related information via text in this population. This study supports other evidence of acceptability of textmessage based health information intervention [38]. This study had a few limitations, all measures were self-reported and therefore the responses were dependent on the participants' honesty and memory in answering the study questions. The sample was small, and the participants were not balanced in gender, student's classification and race/ethnicity. Future studies should consider using multiple recruitment approaches to attract a more balanced group of participants. The intervention focused on three broad topics and this may explain the modest results in this study. Lastly, since there was no long-term follow-up for this study, there is no way of measuring if the observed behavior changes had long lasting effects or if they occurred during the intervention period only. Future research should be longitudinal in nature to examine the long-term effect of text delivered messages on dietary habits, perceived stress and awareness of food assistance resources among college students.

\section{Conclusion}

The current study proved that text delivered messages were effective in reducing perceived stress scores, reducing calories from SSB, increasing the intake of fruit and vegetable, and increasing awareness of food assistance resources among college students. Based on these changes, retention and positive evaluation comments made by study participants, text delivered messages were acceptable and effective for this audience. We recommend that future studies use repetitive text messages that include visual aids, as well as have long-term follow-ups to determine long-term behavior change. We also recommend that future studies evaluate diet quality of study participants using 24-hour dietary recall.

\section{References}

1. Worthy SL, Jonkman J, Blinn-Pike L (2010) Sensation-Seeking, RiskTaking, and Problematic Financial Behaviors of College Students. J Fam Econ Issues 31(2): 161-170.

2. Kattelmann KK, Bredbenner CB, White AA, Greene GW, Hoerr SL, et al. (2014) The effects of Young Adults Eating and Active for Health (YEAH): a theory-based Web-delivered intervention. J Nutr Educ Behav 46(6): S27-41.

3. Brunt A, Rhee Y, Zhong L (2008) Differences in Dietary Patterns Among College Students According to Body Mass Index. J Am Coll Heal 56(6): 629-634.

4. Wallace DD, Boynton MH, Lytle LA (2017) Multilevel analysis exploring the links between stress, depression, and sleep problems among twoyear college students. J Am Coll Heal 65(3): 187-196.
5. Strong K, Parks S, Anderson E, Winett R, Davy B (2008) Weight gain prevention: Identifying theory-based targets for health behavior change in young adults. J Am Diet Assoc 108(10):1708-1715.

6. Larson NI, Perry CL, Story M, Neumark-Sztainer D (2006) Food Preparation by Young Adults Is Associated with Better Diet Quality. J Am Diet Assoc 106(12): 2001-2007.

7. Gaines A, Robb CA, Knol LL, Sickler S (2014) Examining the role of financial factors, resources and skills in predicting food security status among college students. Int J Consum Stud 38(4): 374-384.

8. Papadaki A, Hondros G, Scott J, Kapsokefalou M (2007) Eating habits of university students living at, or away from home in Greece. Appetite 49(1): 169-176.

9. Von Bothmer Mik, Fridlund B (2005) Gender Differences In Health Habits And In Motivation For A Healthy Lifestyle Among Swedish University Students. Nurs Heal Sci 7(2):107-118.

10. Davy S, Benes B, Driskell J (2006) Sex differences in dieting trends, eating habits, and nutrition beliefs of a group of midwestern college students. J Am Diet Assoc 106(10): 1673-1677.

11. Kelly N, Mazzeo S, Bean M (2013) Systematic review of dietary interventions with college students: directions for future research and practice. J Nutr Educ Behav 45(4): 304-313.

12. Dehdari T, Kharghani Moghadam M, Mansouri T, Saki A (2013) Survey of daily fruit consumption status among girl students who are living in dormitories and its predictors based on the theory of planned behavior constructs. Razi J Med Sci 20(106): 10-19.

13. Mirabitur E, Peterson KE, Rathz C, Matlen S, Kasper N (2016) Predictors of college-student food security and fruit and vegetable intake differ by housing type. J Am Coll Heal 64(7): 555-564.

14. Larson NI, Neumark-Sztainer DR, Story MT, Wall MM, Harnack LJ, et al. (2008) Fast Food Intake: Longitudinal Trends during the Transition to Young Adulthood and Correlates of Intake. J Adolesc Heal 43(1): 79-86.

15. Smith West D, Bursac Z, Quimby D, Prewitt TE, Spatz T, et al. (2006) Self-Reported Sugar-Sweetened Beverage Intake among College Students. Obesity 14(10): 1825-1831.

16. Rosinger A, Herrick K, Gahche J, Park S (2017) Sugar-sweetened Beverage Consumption Among U.S. Adults, 2011-2014. NCHS Data Brief (270): 1-8

17. Lund H, Reider B, Whiting A, Prichard J (2010) Sleep patterns and predictors of disturbed sleep in a large population of college students. J Adolesc Heal 46(2): 124-132.

18. Fall 2017 Reference Group Executive Summary.

19. Clark CM, Nguyen DT, Barbosa-Leiker C (2014) Student Perceptions of Stress, Coping, Relationships, and Academic Civility. Nurse Educ 39(4): 170-174.

20. Department of Health and Human Services. Healthy People 2020.

21. Fjeldsoe BS, Marshall AL, Miller YD (2009) Behavior Change Interventions Delivered by Mobile Telephone Short-Message Service. Am J Prev Med 36(2): 165-173.

22. Cole-Lewis, Kershaw T (2010) Text messaging as a tool for behavior change in disease prevention and management. Epidemiol Rev 32(1): 56-69.

23. Lenhart A, Purcell K, Smith A, Zickuhr K (2010) Social Media and Mobile Internet Use among Teens and Young Adults. Millennials. Pew Internet Am Life Proj.

24. Napolitano MA, Hayes S, Bennett GG, Ives AK, Foster GD (2013) Using facebook and text messaging to deliver a weight loss program to college students. Obesity 21(1): 25-31. 
25. Aleman AMM, Wartman LK (2009). Online Social Networking on Campus: Understanding What Matters in Student Culture (Review) Rev High Educ 33(2): 301-303.

26. King J (2017) Food Insecurity Among College Students-Exploring the Predictors of Food Assistance Resource.

27. Thompson F, Midthune D, Subar A, Kahle L, Schatzkin A, et al. (2004) Performance of a short tool to assess dietary intakes of fruits and vegetables, percentage energy from fat and fibre. Public Health Nutr 7(8): 1097-1106.

28. Mikolajczyk RT, El Ansari W, Maxwell AE (2009) Food consumption frequency and perceived stress and depressive symptoms among students in three European countries. Nutr J 8(1): 31.

29. CDC - BRFSS - Questionnaires.

30. Knafl K, Deatrick J, Gallo A, Holcombe G, Bakitas M, et al. (2007) The analysis and interpretation of cognitive interviews for instrument development. Res Nurs Health 30(2): 224-234.

31. Body Mass Index (BMI) | Healthy Weight | CDC.

32. Hughes R, Serebryanikova I, Donaldson K, Leveritt M (2011) Student food insecurity: The skeleton in the university closet. Nutr Diet 68(1): 27-32.

33. Kang J, Ciecierski C, Malin E, Carroll AJ, Gidea M, et al. (2014) A latent class analysis of cancer risk behaviors among US college students. Prev Med (Baltim) 64: 121-125.

34. Spring 2016 Reference Group Executive Summary.
35. Shahril MR, Elena WP, Dali W, Lua PL (2013) A 10-week multimoda nutrition education intervention improves dietary intake among university students: cluster randomised controlled trial. J Nutr Metab 11: 658642 .

36. Brown ON, O'Connor LE, Savaiano D (2014) Mobile MyPlate: A Pilot Study Using Text Messaging to Provide Nutrition Education and Promote Better Dietary Choices in College Students. J Am Coll Heal 62(5): 320-327.

37. Richards A, Kattelmann K, Ren C (2006) Motivating 18-to 24-year-olds to increase their fruit and vegetable consumption. J Am Diet Assoc 106(9): 1405-1411.

38. Walker B, Wolf M, Schroeter C (2009) An Examination of College Students' Produce Consumption and Purchasing Behavior: A Case Study in California. J Food Distrib Res 40(1).

39. Han E, Powell LM (2013) Consumption Patterns of Sugar-Sweetened Beverages in the United States. J Acad Nutr Diet 113(1): 43-53.

40. Luger M, Lafontan M, Bes-Rastrollo M, Winzer E, Yumuk V, et al. (2017) Sugar-Sweetened Beverages and Weight Gain in Children and Adults: A Systematic Review from 2013 to 2015 and a Comparison with Previous Studies. Obes Facts 10(6): 674-693.

41. Quick V, Wall M, Larson N, Haines J, Neumark-Sztainer D (2013) Personal, behavioral and socio-environmental predictors of overweight incidence in young adults: 10-yr longitudinal findings. Int J Behav Nutr Phys Act 10(1): 37.

42. Members - College and University Food Bank Alliance.

\section{Your next submission with Juniper Publishers} will reach you the below assets

- Quality Editorial service

- Swift Peer Review

- Reprints availability

- E-prints Service

- Manuscript Podcast for convenient understanding

- Global attainment for your research

- Manuscript accessibility in different formats

( Pdf, E-pub, Full Text, Audio)

- Unceasing customer service

Track the below URL for one-step submission https://juniperpublishers.com/online-submission.php 